\title{
Aplicação de aerogamaespectrometria no mapeamento de corpos máficos e ultramáficos associados a mineralizações de cobre no norte da Bahia
}

\author{
Robson Santos da Purificação* (IGEO/UFBA), Daniel Conceição dos Santos (IGEO/UFBA), Marcos Alberto Rodrigues \\ Vasconcelos (IGEO/UFBA) e Florivaldo de Oliveira Sena (SERVIGEO)
}

Copyright 2016, SBGf - Sociedade Brasileira de Geofísica

Este texto foi preparado para a apresentação no VII Simpósio Brasileiro de Geofísica, Ouro Preto, 25 a 27 de outubro de 2016. Seu conteúdo foi revisado pelo Comitê Técnico do VII SimBGf, mas não necessariamente representa a opinião da SBGf ou de seus associados. É proibida a reprodução total ou parcial deste material para propósitos comerciais sem prévia autorização da SBGf.

\section{Abstract}

This study aims to verify the application of aerial gammaray spectometry to localize mafic ultramafic rocks. The data are collected over Angico's farm, Curaçá County, northern Bahia, Brazil. The region is largely known as copper ore producer from Curaçá's Valley, and by Delgado and Souza (1975) presents numerous mafic and ultramafic rock placed along the the valley. We have observed that the identification is possible only over areas where the underground bodies are relatively shallow and have reasonable dimensions.

\section{Introdução}

A exploração mineral é um processo que se divide em inúmeras etapas algumas delas envolvendo riscos financeiros. Por serem extremamente onerosos a geofísica atua como uma importante ferramenta na redução destes custos e de riscos exploratórios, auxiliando no mapeamento de possíveis corpos portadores de mineralização e indicando melhores locais para alocações de furos de sondagem.

A gamaespectrometria tradicionalmente utilizada como apoio ao mapeamento geológico regional e à prospecção mineral de urânio, experimentou avanços importantes nos últimos anos. Uma das aplicações modernas da gamaespectrometria é a possibilidade de identificar áreas de alteração hidrotermal e com auxílio de outras informações estabelecer relações com processos de mineralização de metais base ( $\mathrm{Cu}-\mathrm{Pb}-\mathrm{Zn})$, além de ouro e prata em vários ambientes geológicos (Shives et al., 2000). O método gamaespectrométrico aéreo tem a vantagem de poder ser aplicado em extensas áreas a baixo custo, permitindo inclusive a possibilidade de mapeamento geológico de áreas de difícil acesso por via terrestre.

O objetivo principal do presente trabalho é verificar a aplicação do método aerogamaespectrométrico na localização e mapeamento de corpos máficos e ultramáficos possivelmente portadores de mineralização de cobre. Os dados utilizados são de alvos localizados na Fazenda Angico no município de Curaçá no norte da Bahia. A região onde está situado o município de Curaçá é conhecida como região cuprífera do Vale do Curaçá e segundo Delgado e Souza (1975) apresenta inúmeros corpos máficos e ultramáficos espalhados por toda a planície do vale e em algumas situações podem ser identificados no terreno pelo solo argiloso de cor cinza escura. A identificação em solo só é possível quando os corpos em subsuperfície. A utilização de métodos geofísicos indiretos mostra-se uma importante ferramenta.

As rochas máficas e ultramáficas da região estão encaixadas em rochas altamente metamorfizadas e migmatizadas integrantes do complexo caraíba que segundo Teixeira (1997) é composto predominantemente por terrenos gnáissicos de alto grau metamórfico, migmatitos e granitoides diversos sendo o complexo portador das rochas mais antigas da região. Este tipo de rocha quando intrudida em meio a gnaisses pode oferecer uma boa resposta espectrométrica principalmente quanto ao teor de potássio, uma vez que as rochas máficas são sabidamente pobres portadoras daquele elemento. Os estudos basearam-se na elaboração de mapas de curvas de contorno a partir de dados gamaespectrométricos aéreos.

\section{Contexto Geológico}

A área de estudo deste trabalho denominada de Fazenda Angico, está localizada no município de Curaçá, norte da Bahia, situada sobre o Cinturão Salvador - Curaçá, integrante do Cráton do São Francisco, apresenta com a ocorrência de dois alvos potencialmente portadores de mineralização de cobre, os alvos Lagoa da Mina - LM e Cercado Velho - CV distantes aproximadamente 800 metros.

O Cinturão Itabuna-Salvador-Curaçá, tem sido objeto de diversos estudos, motivados principalmente pelo seu elevado potencial metalogenético como é o caso dos depósitos de cobre, objeto deste trabalho. Para Misi et al., (2012) essas mineralizações ocorreram no intervalo de 2.100 a $1.850 \mathrm{Ma}$ durante a aglutinação do Cráton do São Francisco associada a interação manto-crosta na formação do paleocontinente Atlântica. Os corpos máficos-ultramáficos estão espalhados pelo Vale do Curaçá, alguns contendo mineralização de cobre de caráter econômico. A figura 6 mostra um mapa geológico simplificado da área de estudo.

\section{Metodologia}

Os dados gamaespectrométricos aéreos foram coletados pela Companhia Baiana de Pesquisa Mineral - CBPM no projeto Riacho Seco - Andorinhas. O levantamento foi realizado ao longo de linhas de voo de produção com direção leste - oeste espaçadas de $250 \mathrm{~m}$ e linhas de voo de controle na direção norte sul espaçadas de 2500m (figura 1) .A altura nominal do levantamento foi de $100 \mathrm{~m}$ acima do terreno e o intervalo médio da 
amostragem foi de $70 \mathrm{~m}(1,0 \mathrm{~s})$. O levantamento foi feito por toda a área do vale do rio Curaçá, no entanto, para este trabalho, os dados utilizados referem-se apenas a área da fazenda Angico, que foram "recortados" do banco de dados original.

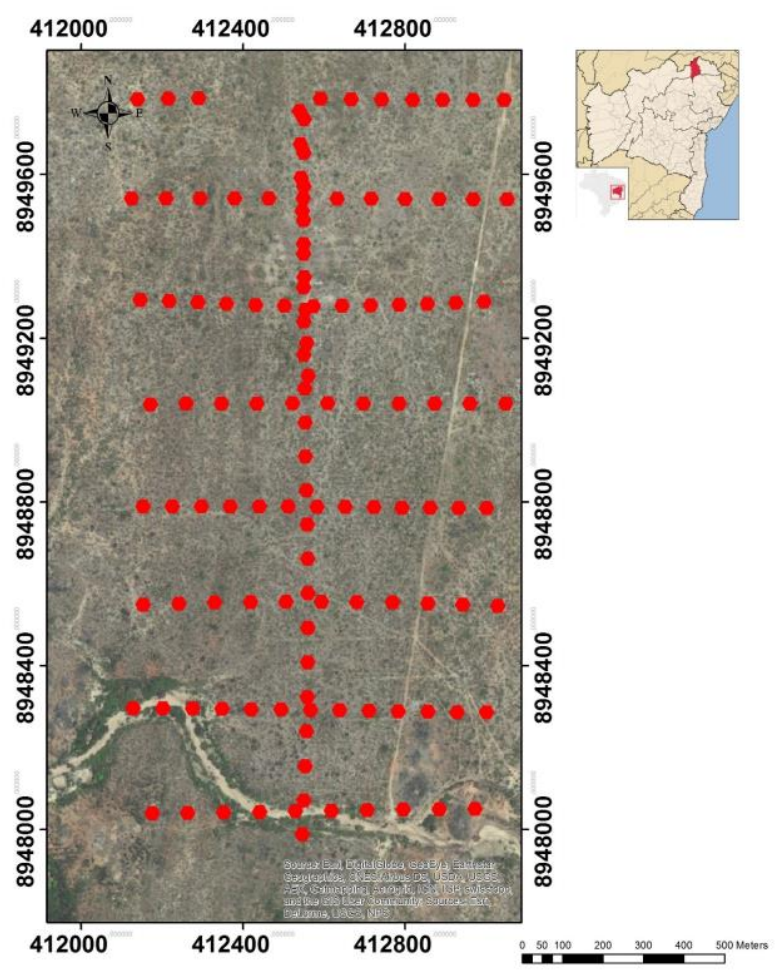

Figura 1: Imagem de satélite da área do estudo com a localização em vermelho dos pontos de medida de dados gamaespectrométricos.

O levantamento foi realizado com avião bimotor de asa fixa, com um sistema de aquisição de dados responsável por armazenar em disco rígido todos os dados registrados. O gamaespectrômetro utilizado foi de 256 canais e o espectro de cada um dos canais foi analisado individualmente para a determinação precisa dos fotopicos de contagem total do potássio, do urânio e do tório. O sistema detector foi constituído por dois conjuntos de cristais de $\mathrm{Nal}(\mathrm{TI})$ um voltado para baixo e outro voltado para cima.

A radiação gama utilizada nos estudos radiométricos é originada a partir do decaimento radioativo, que é um fenômeno aleatório, onde a taxa de decaimento é proporcional ao número de determinado tipo de isótopos presentes num certo instante. A expressão do decaimento radioativo é dada por:

$$
\int_{N_{0}}^{N} \frac{D N}{N}=-\lambda \int_{0}^{t} d t
$$

onde, $\lambda$ é a constante de decaimento radioativo, $N_{0} 0$ número de radionuclideos presentes no tempo $t=0$ e $\mathrm{N}$ o número de nuclideos presentes no tempo t.
Os dados foram corrigidos para remoção dos ruídos de fundo cósmico e da aeronave e para a correção do radônio atmosférico e a pós as devidas correções a taxa de contagem total foi convertida para as concentrações aparentes dos radioelementos.

\section{Resultados}

Após o processamento, os dados foram interpolados com o método de mínima curvatura expressos através de mapas de cores para a concentração de Potássio(\%), de Urânio (ppm) e de Tório (ppm).

O mapa do canal do potássio (figura 2) mostra um enriquecimento deste elemento nas porções sudoeste e sudeste, apresentando picos de $3,41 \%$, os baixos de potássio mostram-se localizados sobre os alvos. $\mathrm{Na}$ porção sudeste os altos ocorrem no extremo sul e decrescem à medida que se caminha para o norte onde os altos são interrompidos pela ocorrência de baixa concentração de potássio na região do alvo Lagoa da Mina. Na porção sudoeste os altos também ocorrem no extremo sul da área e decrescem apresentando comportamento linear até a parte norte da área.

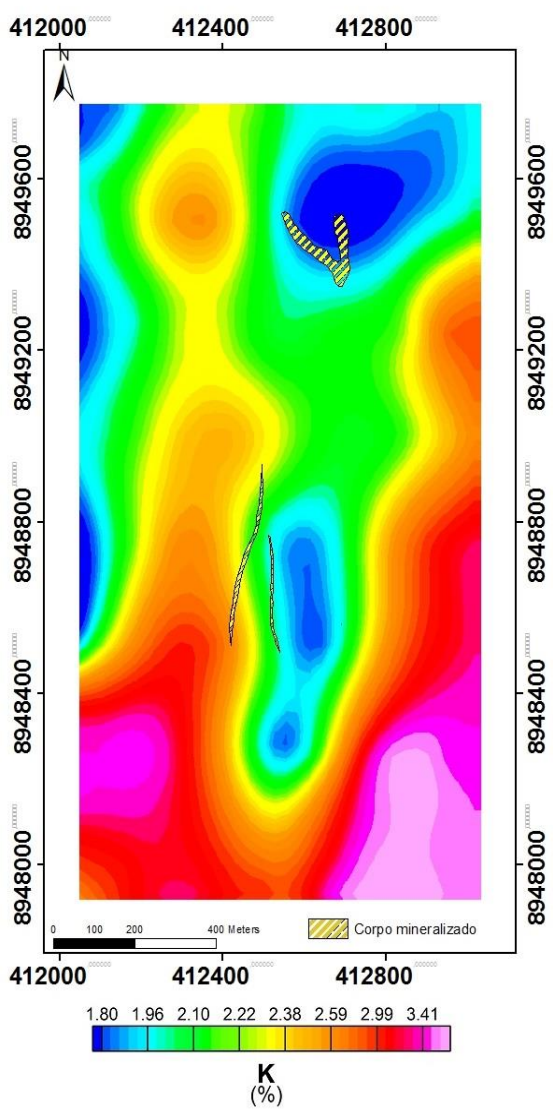

Figura 2: Mapa de concentração de $K(\%)$ com localização dos corpos mineralizados mapeados em superfície.

O mapa do canal do urânio (figura 3) apresenta altos valores na porção central com deslocamento a oeste e na parte sudeste, sobre o alvo Lagoa da Mina há baixa concentração enquanto, o alvo Cercado Velho está 
localizado em uma área de concentração intermediária. As maiores concentrações de urânio são da ordem de 0,92 ppm e ocorrem na porção central.

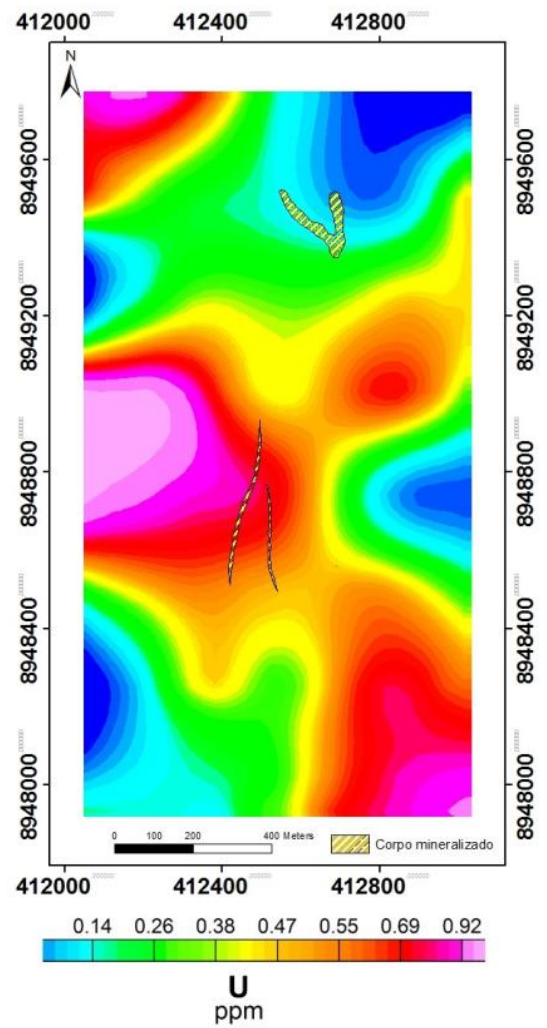

Figura 3: Mapa da concentração de U (ppm) com localização esquemática dos corpos mineralizados mapeados em superfície.

O mapa da concentração de tório (figura 4) apresenta altos nas porções oeste, leste e sul. A parte central da área apresenta baixa concentração de tório coincidindo com a posição do alvo Cercado Velho e estendendo-se até o extremo norte. Os maiores valores observados para a concentração do tório foram da ordem de 13,95 ppm e ocorrem nas porções sudeste e extremo oeste.

Dos isótopos radioativos objeto de estudo na gamaespetrometria, o potássio é o mais comum na constituição das rochas e nem sempre ocorre associado a Th e U. Segundo Ribeiro (2013) os teores de isótopos radioativos em rochas máficas e ultramáficas é baixo quando comparado com os demais tipos de rochas. $\mathrm{O}$ potássio aparece com abundância média de $2,32 \%$ na crosta superior. O urânio com 2,7 ppm e o tório com 10,5 $\mathrm{ppm}$. É possível observar que as baixas concentrações de $\mathrm{K}(\%)$ estão fortemente associadas à presença de corpos máficos e ultramáficos dos alvos Lagoa da Mina e Cercado Velho. Desta maneira, os mapas de concentração de $\mathrm{K}$ mostram-se mais propícios para a correlação com possíveis zonas mineralizadas de cobre da região.

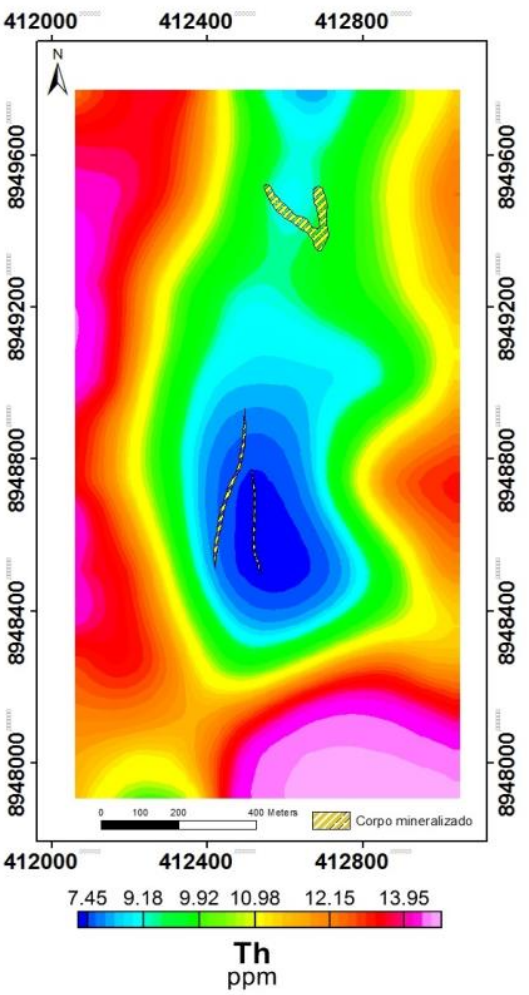

Figura 4: Mapa da concentração de Th(ppm) com localização esquemática dos corpos mineralizados mapeados em superfície.

Foi composto um mapa ternário com o sistema de cores RGB (figura 5). Neste tipo de composição, os valores relativos às cores primárias, vermelho, verde e azul, são somados de tal modo que as cores mais saturadas da imagem (áreas mais brancas) refletem intensidade de radiação mais altas enquanto que porções com cores mais escuras representam intensidades mais baixas nos três canais. De maneira geral o mapa ternário apresentase semelhante ao canal de urânio, com altos valores de radiação localizados no extremo sul com tendência de crescimento na direção leste.

Os resultados obtidos com os mapas de concentração dos radioelementos e o mapa ternário fornecem informações importantes para a exploração mineral, como a localização de zonas de interesse devido principalmente a características já conhecidas dos alvos de estudo como 0 baixo teor radioelementos característico de rochas básicas (máficas e ultramáficas).

A principal ocorrência de potássio em associações minerais se dá nos feldspatos potássicos. As rochas que apresentam os maiores teores de potássio são rochas ígneas félsicas como os granitoides. Para rocas ultramáficas e seus equivalentes metamórficos o teor é considerado extremamente baixo (Ribeiro, 2013). 


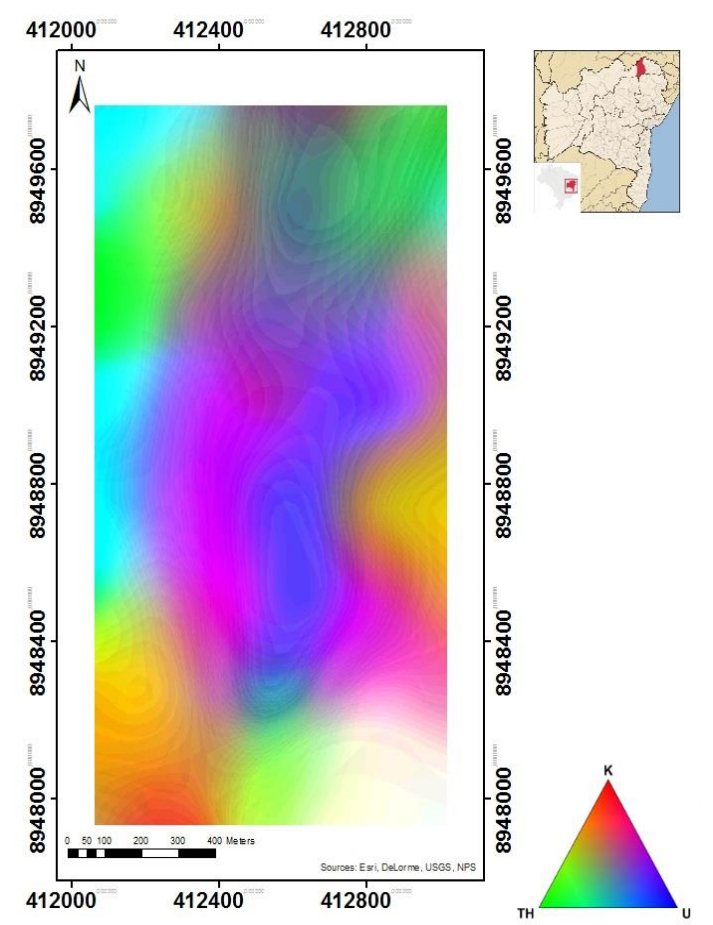

Figura 5: Mapa ternário das concentrações $K(\%), U(p p m)$ e Th(ppm) composto no sistema de cores RGB.

$\mathrm{Na}$ crosta continental, o urânio apresenta um valor médio de $1,3 \mathrm{ppm}$, sendo sua concentração maior na parte superior da crosta $(2,7 \mathrm{ppm})$ do que na inferior $(0,2 \mathrm{ppm})$. O tório, por sua vez, apresenta valor médio de $5,6 \mathrm{ppm}$ ao longo da crosta continental, podendo atingir teor de até $10,5 \mathrm{ppm}$ na parte superior enquanto que na parte inferior, bem mais exaurida, a concentração de tório é de aproximadamente 1,2 ppm (Rudnick \& Gao 2004).

\section{Discussão e Conclusões}

A análise dos dados aerogamaespectrométricos referentes a região da fazenda Angico permitiu identificar duas assinaturas distintas uma de baixo radiométrico nas posições dos alvos e outra com altos radiométrico ocorrendo nos terrenos gnáissicos e nas intrusões graníticas da região. Com o estudo dos mapas de concentração de $\mathrm{K}(\%)$ (figura 2) e do Th(ppm) (figura 4) é possível mapear as áreas de ocorrência de rochas máficas-ultramáficas, associadas a baixas concentrações destes elementos. O mapa de concentração do urânio (figura 3) não apresenta características semelhantes aos mapas de potássio e tório. Não é possível delimitar as regiões dos alvos, provavelmente devido a característica de solubilidade do urânio e de sua mobilidade na superfície com as águas superficiais. Nota-se que as maiores concentrações ocorrem justamente no leito do rio intermitente que existe na área de estudo. O mapa ternário apresenta os teores mais elevados de radioisótopos no extremo sul da área com forte crescimento para leste sobre a região cuja geologia superficial e a aluvião nas regiões dos alvos ocorre baixas concentrações (cores mais escuras) formando um lineamento norte-sul na porção central da área do estudo.

Quando os mapas das concentrações dos elementos e o mapa ternário são confrontados com o mapa geológico da região (figura 6) é possível verificar que as assinaturas radiométricas estão muito bem definidas no caso especifico do mapa de concentração do potássio os altos lindados e muito bem definidos concordantes com a disposição dos corpos graníticos mapeados em superfície. No caso do Th, de maneira geral os teores são baixos em toda a região mas evidenciam de maneira precisa o posicionamento dos corpos de interesse.

A assinatura radiométrica dos corpos máficos ultramáficos ficou evidenciada neste trabalho e pode ser utilizada para a localização desses corpos em regiões onde eles estejam ligados a alguma mineralização economicamente interessante. Corpos máficos estão fortemente associados à presença de mineralizações, seja de cobre como ocorre no vale do rio Curaçá, seja de cromo e níquel como ocorrem no vale do rio Jacurici, ambos na Bahia. Grande parte do território nacional já possui dados gamaespectrométricos aéreos levantados por órgãos governamentais de fomento e regulação da mineração e órgãos federais como o DNPM e CPRM o que torna o processo menos oneroso e eficiente na etapa inicial de prospecção destes corpos, principalmente em áreas de difícil acesso.

\section{Agradecimentos}

Os autores agradecem à Mineração Caraíba S.A. pela disponibilização dos dados para a realização deste trabalho.

\section{Referências}

Bello, V. B. 2013. Aerogamaespectrometria e Suas Aplicações no Mapeamento Geológico. Revista Terra e Didática, São Paulo(SP), vol. 10: 29-51.

Delgado, I. M e Souza, J. D. 1975. Projeto Cobre-Curaçá: Relatório Final, Geologia Econômica do Distrito Cuprífero do Rio Curaçá, Bahia, Brasil. Salvador. CPRM. 30v. 419p.

Misi, A., Teixeira, J.B.G., Sá, J.H.S. 2012. Mapa metalogenético digital do Estado da Bahia e Principais Províncias Minerais. Salvador: CBPM, 244p

Rudnick R., Gao S. 2004. Composition of the continental crust. In: Holland H.D., Turekian N.N. eds. Treatise on geochemistry. Per Oxford: Elsevier Pergamon. vol.3:1-64.

Shives R.B.K., Charnonneau B.W., Ford K.L. 2000. The detection of potassic alteration by gamma-ray spectrometry-Recognition of alteration related to mineralization. Geophysics, 65p.

Teixeira, L. R. (1997). O Complexo Caraíba e a Suíte São José do Jacuípe no Cinturão Salvador-Curaçá (Bahia, Brasil): Petrologia, Geoquímica e Potencial Metalogenético.Tese (doutorado). Universidade Federal da Bahia. Salvador(BA). 188p. 


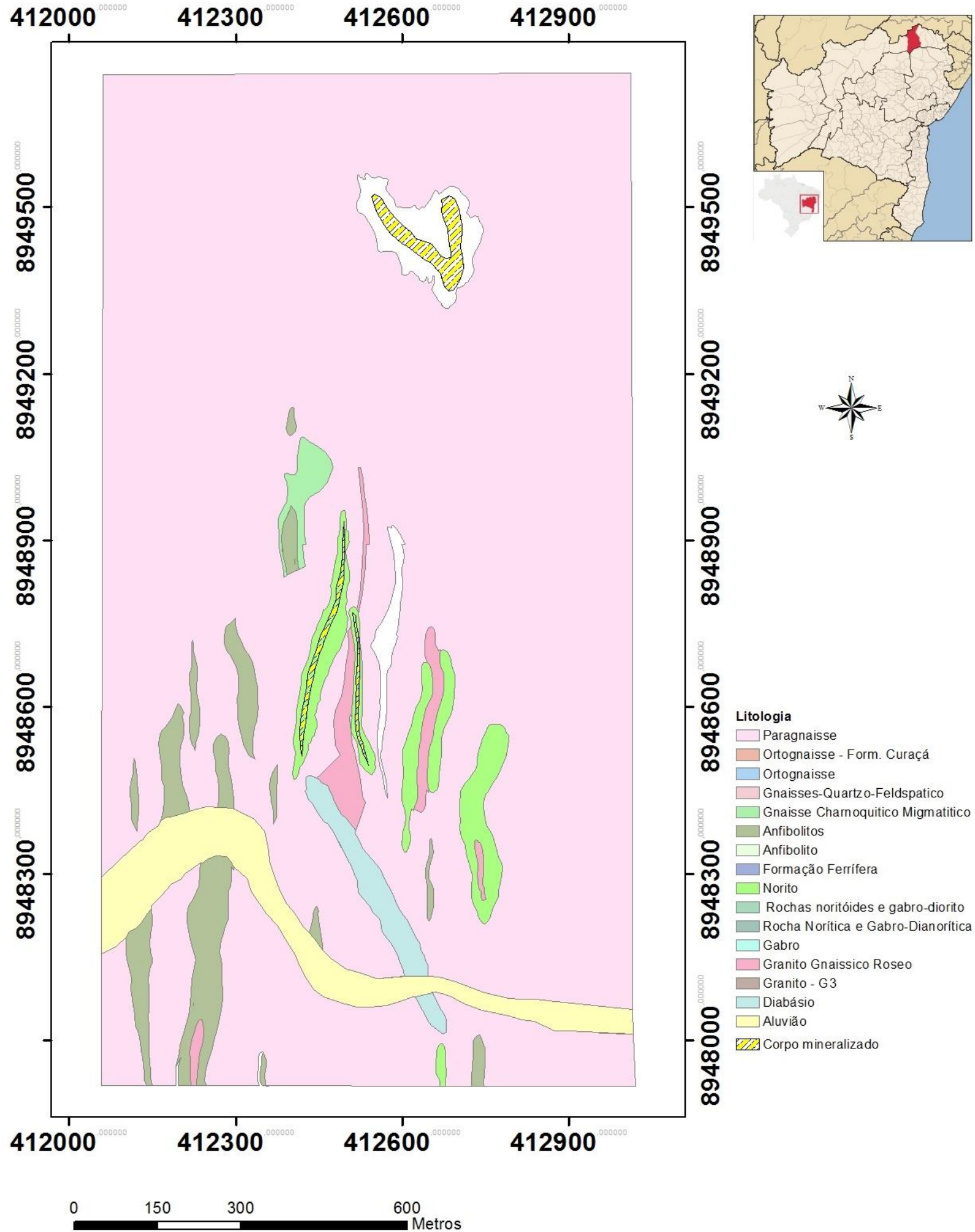

Figura 6: Mapa geológico simplificado da área de estudo. 